\title{
Silah hedef atama problemi için uyarlanmış yerel arama ile yeni bir melez genetik algoritma
}

\author{
A new hybrid genetic algorithm with local search adapted for weapon target assignment \\ problem
}

Osman PALA*1,a

${ }^{1}$ Karamanoğlu Mehmetbey Üniversitesi, İktisadi ve İdari Bilimler Fakültesi, Ekonometri Bölümü, 70100, Karaman

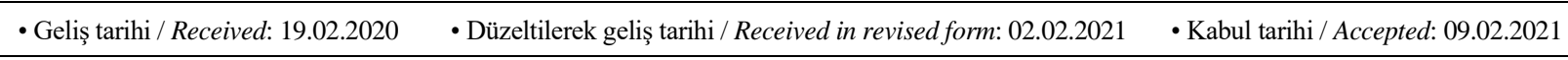

\section{Öz}

Silah Hedef Atama Problemi, np-zor bir optimizasyon problemidir. Problemdeki amaç, hedeflere uygun silahların atanması ile toplam hedeflerin hayatta kalma değerini minimize etmektir. Doğrusal olmayan fonksiyonlar ve tam sayılı karar değişkenleri ile problem, çözüm açısından oldukça zor yapıdadır. Bu nedenle problem, çoğunlukla sezgisel yaklaşımlar ile çözülmeye çalışılmaktadır. Çalışmada, problemin çözümü için probleme özgü yerel arama prosedürüne sahip yeni bir Melez Genetik Algoritma önerilmiştir. Literatürden elde edilen örnek problemlerin çözümüyle, önerilen Melez Genetik Algoritmanın etkinliği değerlendirilmiştir. Sonuçlar incelendiğinde geliştirilen yaklaşımın problemin çözümünde yüksek başarıma sahip olduğu görülmüştür.

Anahtar kelimeler: Genetik algoritma, Silah hedef atama problemi, Yerel arama prosedürü

\begin{abstract}
The Weapon Target Assignment Problem is a np-hard optimization problem. The aim of the problem is to minimize the survival value of total targets by assigning appropriate weapons to the targets. With non-linear functions and integer decision variables, the problem is quite difficult in terms of solution. Therefore, the problem is mostly tried to be solved by heuristic approaches. In the study, a new Hybrid Genetic Algorithm with a problem-specific local search procedure is proposed to solve the problem. The efficiency of the proposed Hybrid Genetic Algorithm was evaluated by solving the sample problems obtained from the literature. When the results were examined, it was seen that the approach developed had high success in solving the problem.
\end{abstract}

Keywords: Genetic algorithm, Weapon target assignment problem, Local search procedure 


\section{Giriş}

Silah Hedef Atama Problemi (SHAP) önemli bir optimizasyon problemi olup çoğunlukla askeri alanda karşılaşılmakla birlikte aynı zamanda işletmelere yönelik reklam bütçesi oluşturma (Çetin ve Esen, 2006) gibi farklı alanlarda da ortaya çıkabilmektedir. SHAP probleminde ifade edilen silahlar, nesne ve hedefler de, hedef nesne olarak düşünülerek problem farklı amaçlar için kullanılabilmektedir. Birden çok nesnenin bir hedef nesneye atanabilmesi, hedef nesnelerin üzerlerine atama yapılarak belirli limitlere kadar doyurulması ve limit aşımında ilgili hedef nesneye yeni atamanın fayda sağlamaması şeklinde özellikleri ile problem çok farklı alanlarda uygulanabilecek genel bir matematiksel modele sahiptir.

SHAP probleminin askeri alanda kullanımında ise değişik türde silahların, farklı değerlere sahip hedeflere ataması yapılarak hedeflerin toplamının sağ kalma değerlerini en küçüklemek amaçlanmaktadır (Ahuja vd., 2007).

Manne'nin (1958) ilk kez tanımladığı SHAP, matematiksel modelinin barındırdığı doğrusal olmayan fonksiyonlar ve sadece tam sayı değer alabilen karar değişkenleri nedeniyle, klasik matematiksel metotlarla çözümü oldukça zor olan bir problemdir. Özellikle kısa sürede çözüm beklenen askeri sistemlerde bu metotların kullanımı mümkün olmamaktadır. $\mathrm{Bu}$ nedenle problemde en iyi değere yakınsayan ve hızlı çözüm üreten sezgisel yaklaşımlar tercih edilmektedir (Kline vd., 2019).

Sezgisel Algoritma ile SHAP'ın ele alındığ 1 çalışmalar incelendiğinde; Lee vd., (2002) bağışıklığa dayanan Karınca Kolonisi Optimizasyonu (KKO) ile problemi ele almışlardır. Önerdikleri yöntemde KKO'nun arama anlayışı ve yerel optimumları aşabilme gücünü bağışıklık sistemi yaklaşımının küçük bölgelerde optimumu bulabilme yeteneğiyle birleştirmişler ve örnek problemlerde başarılı sonuçlara ulaşmışlardır. Lee vd., (2003) yerel arama ile güçlendirilmiş Genetik Algoritma (GA) ile SHAP için yeni bir yaklaşım geliştirmişlerdir. Oluşturulan senaryolar ve örnek problemlerin çözülmesi sonucunda önerilen yaklaşımın bilinen yaklaşımlara göre daha iyi sonuçlar üretebildiği ifade edilmiştir. $\mathrm{Fu}$ vd., (2006) tarafından yapılan çalışmada GA ve KKO'nun birlikte kullanıldığı bir melez GAKKO algoritması önerilmiştir. Geliştirilen metotta ilk önce GA ile çeşitlilik sağlanmakta sonra ise KKO ile optimuma ulaşılmaya çalışılmaktadır. Bölgesel hava savunma sistemleri düşünülerek oluşturulan örnek problemlerin çözümünde önerilen yaklaşımın diğer metotlara göre üstünlüğü ortaya çıkmıştır. Lu vd., (2006) GA'da yaptıkları iyileştirmelerle askeri deniz filosunun hava savunma sistemlerinin ele alındığ 1 çalışmada SHAP olarak modellenen problemi etkin bir şekilde çözdüklerini belirtmişlerdir. Önerilen algoritmada başlangıç popülasyonu, seçim süreçleri ve parametre adaptasyonlarında iyileştirmeler yapılmıştır. Zeng vd., (2006) çalışmalarında GA ile Parçacık Sürü Optimizasyonu (PSO) algoritmalarını birlikte kullanarak SHAP için yeni bir yaklaşım üretmişlerdir. Arama yaklaşımında açgözlü arama konseptini kullanan yöntem ile örnek problemlerde bilinen sezgisel yöntemlere göre daha iyi sonuç elde edilmiştir. Yanxia vd., (2008) SHAP için KKO'yu kullanmışlardır. Algoritmada probleme özgü adaptasyonlar gerçekleştirdikleri çalışmalarında ürettikleri örnekte 20 adet silah bulunurken 6 adet hedef yer almaktadır. Buna göre önerdikleri yaklaşımla örnek problemin çözümünde etkin sonuç elde edildiğinin altı çizilmiştir. Zhou vd., (2016) tarafindan yapılan çalışmada farklı mesafedeki hedef ve farklı atış menzillerine sahip silahlara göre ele aldıkları SHAP için GA ile destekledikleri ayrı PSO'yu önermişlerdir. Çalışmada GA'nın mutasyon ve çaprazlama operatörlerinden faydalanılırken kısıt aşımını engellemek için ceza fonksiyonundan faydalanılmıştır. Simulasyon sonuçlarına göre önerilen yaklaşımın klasik GA ve PSO'ya göre daha iyi sonuçlar ürettiği ifade edilmiştir. Yang vd., (2016) çalışmalarında SHAP matematiksel modelini kullanarak kara konuşlu hava savunma sistemlerinin hedeflere karşı kullanımı problemi üzerinde durmuşlardır. Önerdikleri adaptif bağışıklığa dayalı GA yöntemi ile test probleminde yakınsama hızı ve çözüm kalitesi açısından bilinen sezgisellere göre daha iyi sonuç elde etmişlerdir. Hongtao ve Fengju (2016) askeri deniz filosunun konumlanmas1 ve filoya ait hava savunma sistemlerinin farklı tipte hedefler karşısındaki savunma stratejileri üzerinde durdukları çalışmalarında problemi SHAP matematiksel modeli üzerinden incelemişlerdir. Adaptif kaos teorisi ve paralel popülasyon yaklaşımından faydalanan yeni geliştirdikleri klonal seleksiyon algoritması ile oluşturdukları savaş senaryolarında başarılı sonuçlar elde ettiklerini ifade etmişlerdir. Sonuç vd., (2017) SHAP için paralel Benzetilmiş Tavlama (BT) geliştirdikleri çalışmalarında simülasyonlarla oluşturdukları örnek problemleri önerdikleri yöntemle klasik BT'ye göre daha hızlı ve etkin bir şekilde çözebildiklerini belirtmişlerdir. Li vd., (2017) çalışmalarında SHAP için modifiye 
edilmiş KKO modeli önermişlerdir. Problemin iki amaçlı olarak ele alındığı modelde birinci amaç hasar maksimizasyonu iken diğeri ise kullanılan silah maliyetini minimize etmektir. Kara konuşlu hava savunma sistemlerine göre oluşturulan senaryolarda önerilen yöntem ile literatürde yer alan diğer sezgisellere göre daha iyi sonuç alındığının altı çizilmiştir. Kutucu ve Durgut (2018) SHAP için Yapay Arı Kolonisi (YAK) ve BT'yi birleştirerek elde ettikleri yeni bir melez sezgisel algoritma önermişlerdir. Önerilen algoritmada seçim yöntemleri olarak rulet tekerleği, turnuva ve budama yaklaşımları ile komşuluk üretmede ise yer değiştirme, tersine çevrim ve araya ekleme ayrı ayrı denenmiştir. Literatürde yer alan test problemlerini klasik yaklaşımlara göre daha başarılı çözdüklerini ifade etmişlerdir. Hu vd., (2018) SHAP için havadan havaya çarpışma senaryosuna göre farklı tipte askeri kısıtları ve amaç fonksiyonları bulunan matematiksel modeller oluşturmuşlar ve geliştirdikleri iyileştirilmiş KKO ile çözüm önermişlerdir. Çalışmalarında problemi dinamik olarak ele almışlar ve gerçekleştirdikleri simülasyon ile önerilen yaklaşımın etkinliğini göstermişlerdir. Li vd., (2018) çalışmalarında SHAP problemini çok amaçli olarak ele almışlardır. Amaçlardan bir tanesi klasik SHAP amaç fonksiyonu olurken diğeri ise kullanılan silah sayısını minimize etmektir. Problemin çözümünde çok amaçlı evrimsel algoritma ile Pareto etkin sınırı elde etmişlerdir. Algoritmada probleme özgü ayrışım mekanizması geliştirerek literatüre katkıda bulunmuşlardır. Chang vd., (2018) SHAP'ın çok aşamalı bir türü olan ve dinamik SHAP olarak adlandırılan problemin çözümü için iyileştirilmiş YAK algoritmas1 önermişlerdir. Dört farkl1 sezgisel tabanlı kural ile güçlendirdikleri algoritmaları ile farklı boyutlarda simule edilen örnek problemleri çözmüşler ve etkin çözüme ulaştıklarını ifade etmişlerdir. Hocaoğlu (2019) tarafindan yapılan ve kara konuşlu hava savunma sistemlerinin olas1 tehditlere göre

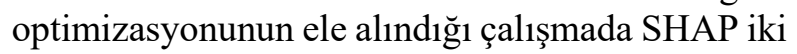
amaçlı bir problem olarak ele alınmıştır. Birinci amaç klasik olarak hedeflerin toplam hayatta kalma olasılık değerlerini minimize etmekken ek olarak minimum sayıda silah kullanılması hedeflenmiştir. Kullanılan kural tabanlı yaklaşımla oluşturulan senaryolarda hızlı ve etkin çözümler elde edildiği belirtilmiştir. SHAP'1 konu alan ve Kline vd., (2019) tarafından yapılan çalışmada problemin gerçek hayatta farklı tipte problemlere değişik türde varsayımlar altında nasıl uyarlandığ 1 ve bu ortaya çıkan yeni problemleri ele alan çözüm yöntemlerinin bu durumda nasıl geliştiği karşılaştırmalı bir şekilde incelenmiştir. Wang vd.,
(2019) çalışmalarında kara hedeflerine taaruz tipinde modelledikleri SHAP için başlangıç popülasyonu seçiminde değişkenlerin değer aralıklarına göre problem çözüm uzayını sinırladıkları GA ile örnek problemlerde iyi performans elde ettiklerini ifade etmişlerdir. Sonuç (2020) tarafından modifiye edilmiş Karga Arama Algoritmas1 (KAA) ile SHAP için yeni bir algoritma önerilmiştir. Algoritmada belirli iterasyon sayısı boyunca iyileşme sağlanmadığında algoritmanın çözüm uzayında yeni bir noktadan başlamasını sağlayan bir parametre ile iyileştirilme yapıldığı ifade edilmiştir. Literatürde yer alan test problemlerinde güncel algoritmalara göre daha iyi sonuçlar elde edildiği belirtilmiştir.

SHAP, özellikle günümüzde gelişen füze sistemleri, insansız hava araçları gibi askeri teknolojiler ile güncelliğini artıran önemli bir problem tipidir. Bu çalışmadaki temel amaç, statik SHAP çözümü için yüksek performans ve başarıma sahip bir sezgisel algoritma geliştirmektir. Bu bağlamda SHAP'a özgü yerel arama prosedürüne sahip yeni bir Melez GA yaklaşımı geliştirilerek literatüre katkı sağlanması hedeflenmiştir. Literatürde farklı çalışmalarda yer alan örnek problemler kullanılarak geliştirilen yaklaşımın performansı değerlendirilmiştir.

\section{Materyal ve metot}

\subsection{Silah hedef atama problemi}

SHAP ilk kez Manne'nin (1958) çalışmasında tanımlanmıştır. Problemde farklı özellikte silah ve bunların farklı ihtimallerde saf dışı bırakabileceği hedefler bulunmakta ve amaçlanan ise hedeflerin toplam saf dışı kalma ihtimal değerini en büyüklemektir. Problem bir başka açıdan hedeflerin toplam sağ kalma ihtimal değerlerini en küçüklemek şeklinde de ifade edilebilmekte ve problemin bu haline göre modellenmiş hali aşağıdaki gibidir.

Amaç Fonksiyonu:

$$
\operatorname{Min} \mathrm{Z}=\sum_{j=1}^{n} V_{j} \prod_{i=1}^{m} q_{i j}^{x_{i j}}
$$

Kisitlar:

$$
\begin{aligned}
& \sum_{j=1}^{n} x_{i j} \leq W_{i}, \quad i=1, \ldots, m \\
& x_{i j} \in \mathbb{Z}_{+}
\end{aligned}
$$

Problemin matematiksel modelinde yer alan amaç fonksiyonu ile $\mathrm{n}$ adet hedefe kilitlenen $\mathrm{m}$ adet silah 
türünün $\mathrm{V}_{\mathrm{j}}$ hedef değeri, $\mathrm{q}_{\mathrm{ij}}$ silahın hedefi saf dış1 bırakma ihtimali, $\mathrm{x}_{\mathrm{ij}}$ hedefe kilitlenen silah türü adeti değişkenlerine göre hedeflerin toplam sağ kalma ihtimal değerlerini en küçüklemek amaçlanmaktadır. Kısıtlar ile $\mathrm{W}_{\mathrm{i}}$ silah türlerine ait sayılara göre kısıtlamalar ve karar değişkeni $x_{i j}$ 'nin alabileceği değerler tanımlanmaktadır.

\subsection{Genetik algoritma}

Holland'ın (1975) ortaya attığı GA'da evrim kavramından yola çıkılarak nesillerin zaman geçtikçe iyileşme süreci, optimizasyon problemlerinde uygun çözümlerin iterasyonlar boyunca iyileşmesi için uyarlanmıştır.

GA'da probleme dair uygun çözümler kromozom adı verilen ve genlerden oluşan yapılarla temsil edilmektedir. Problem için çalışma dahilinde kullanılan gen kodlama yapısı beş silah tipi ve üç hedef bulunan örnek problem için Tablo 1'deki gibidir.

Tablo 1. Kromozom yapis1

\begin{tabular}{l|l|l|l|l|l}
\hline Kromozom X & 2 & 2 & $\mathbf{1}$ & $\underline{\mathbf{3}}$ & $\mathbf{1}$ \\
\hline Kromozom Y & 1 & 2 & 3 & 2 & 3 \\
\hline
\end{tabular}

Tablo 1'de Kromozom X'de üçüncü ve beşinci sıralarda 1 değerinin yer alması 3. ve 5. silahın birlikte 1 . hedefe yöneldiği dördüncü sirada 3 değerinin yer alması ise üçüncü hedefe dördüncü silahın kilitlendiğini ifade etmektedir.

Çalışmada kullanılan GA yaklaşımı aşağıdaki dört safhada gerçekleşmektedir.

\section{Safha 1: Başlangıç popülasyonu oluşturma}

GA'da her zaman için algoritmanın başlangıç popülasyonu bulunmak durumundadır. Çalışma kapsamında bu popülasyon tek düze dağılıma göre şekillenmiştir. Elde edilen her bir kromozomun uygunluk fonksiyonu değeri SHAP matematiksel modelindeki amaç fonksiyonu kullanılarak hesaplanmaktadır.

\section{Safha 2: Kromozom seçimi}

Kromozom topluluğundan yeni kromozomların üretilmesinde ise ilk önce üretim işleminde kullanılacak kromozomların seçimi gerekmektedir. Çalışma dahilinde iyi kromozomların daha yüksek olasılıkla seçim ilkesini benimseyen rulet tekerleği kullanılmıştır. Seçim işleminde GA'da önemli bir yaklaşım olan elitizmden yararlanarak biri elit diğeri de popülasyonun genelinden kromozom seçimi gerçekleştirilmiştir. Çalışmada kullanılan elitizm yaklaşımına göre popülasyonlardaki en iyi kromozomları korumak için ilk \%5'lik dilime giren kromozomların her bir iterasyonda yeni popülasyona direk aktarımı sağlanmıştır. Seçim sonucunda elde edilen kromozomlar tamamen ayn olduğunda ise rassal olarak yeni bir kromozom seçim için oluşturularak kullanılmıştır. Burada amaçlanan benzer kromozomların popülasyonda sıklaşmasının önüne geçerek çeşitliliği artırmaktır.

\section{Safha 3: Çaprazlama}

Seçim sonrası elde edilmiş kromozomları kullanarak yeni kromozom oluşturma işlemi ise çaprazlama olarak ifade edilmektedir. Çalışma kapsamında Hoff vd. (1996) tarafindan kullanilan gen bazlı çaprazlama tercih edilmiştir. Çalışmada kullanılan GA yönteminde her iki kromozomdan eşit olasılıkla olacak şekilde gen aktarımı yeni kromozoma yapılmıştır. Tablo 2'de GA'da çaprazlama işlemi örneği bulunmaktadır.

Tablo 2'ye bakıldığında her bir gen için tek düze dağılıma göre oluşturulan rassal sayı 0.5 'ten küçük olduğunda Kromozom X'in ilgili geni, rassal say1 $0.5^{\prime}$ ten büyük olduğunda ise Kromozom Y'nin ilgili geni yeni oluşturulan Kromozom Z'ye geçmiştir. Örnek olarak birinci siralarda Kromozom X'de 2 ve Kromozom Y'de 1 değerleri yer almaktadır. Birinci sıradaki rassal sayı 0.5 'ten az olmas1 sebebiyle Kromozom $X^{\prime}$ in geni, Kromozom Z'ye aktarılan değer olmuştur. Kromozom Z'ye üçüncü gen olarak ise rassal say1 0.85 'e bağlı olarak Kromozom Y'ye ait gen aktarılmıştır.

Tablo 2. Kromozom çaprazlama işlemi

\begin{tabular}{l|c|c|c|c|c}
\hline Kromozom & $\underline{2}$ & $\underline{1}$ & 1 & $\underline{3}$ & 2 \\
\hline Kromozom & 1 & 2 & $\underline{3}$ & 2 & $\underline{3}$ \\
\hline Rassal Sayı & 0.13 & 0.34 & 0.85 & 0.23 & 0.88 \\
\hline Kromozom & 2 & 1 & 3 & 3 & 3 \\
\hline
\end{tabular}

Çalışma kapsamında, GA'da popülasyondaki her bir kromozom için çaprazlamanın gerçekleşme olasılık değeri, Lee vd. (2003) tarafindan da SHAP için kullanılan, 0.8 olarak belirlenmiştir. Bu şekilde belirli sayıda eski popülasyondaki kromozom yeni popülasyona değişmeden aktarılmış olmaktadır.

\section{Safha 4: Mutasyon}

GA yaklaşımında son işlem olarak ise popülasyondaki çeşitliliği artırmak için kullanılan mutasyon işlemi bulunmaktadır. Çalışma 
kapsamında iki genin karşılıklı yer değiştirmesine dayalı mutasyon, Lee vd. (2003) tarafindan SHAP için önerildiği şekilde, 0.4 olasıllkla popülasyon için kullanılmıştır.

Öte yandan popülasyonun çeşitliliğini sağlamak adına mutasyon safhasindan sonra her 10 iterasyonda bir olmak üzere popülasyonda tüm genleri aynı olan kromozomlardan sadece bir tanesi popülasyonda tutularak diğerleri atılmış ve yerlerine rassal olarak oluşturulan yeni kromozomlar eklenmiştir.

\subsection{Yerel Arama Algoritması}

Çalışma kapsamında GA'nın tüm safhaları tamamlandiktan sonra her bir iterasyonda en iyi uyum değerine sahip bir adet kromozom üzerinde yerel arama algoritması kullanılarak daha iyi sonuç aranmıştır. Aynı kromozomun tekrar yerel arama algoritmasında kullanılmasını önlemek için yerel arama algoritmasında kullanılan kromozomların bulunduğu bir tabu listesi eklenmiştir.

Yerel arama algoritmasında dört farklı yaklaşım ele alınmıştır. Bunlardan üçü sıklıkla kullanılan ve aynı zamanda Kutucu ve Durgut (2018) tarafindan da SHAP için önerilen komşuluk üretme yaklaşımlarıdır. Komşuluk üretme algoritmalarından ilki yer değiştirme olup, rassal olarak belirlenen iki konumdaki değerlerin değiştirilmesine dayanmaktadır. İkincisi ise tersine döndürme olarak adlandırılmakta ve rassal olarak belirlenen başlangıç noktası ile bitiş noktasının aralığında bulunan değerlerle birlikte tersine çevrilmesine dayanır. Son olarak üçüncü komşuluk üreten yaklaşım ise araya sokma ile ifade edilmekte ve seçilen iki konumdaki değerlerden bir tanesinin diğerinin sağına eklenmesi ile gerçekleştirilmektedir. Her üç yaklaşıma dair örnekler Tablo 3'te verilmiştir.

Tablo 3. Komşuluk üreten yaklaşımlar

\begin{tabular}{|c|c|c|c|c|c|}
\hline \multicolumn{6}{|c|}{ Yer Değiştirme ile Komşuluk Üretme } \\
\hline Eski Kromozom & $\underline{1}$ & 2 & 3 & $\underline{4}$ & 5 \\
\hline Yeni Kromozom & $\underline{4}$ & 2 & 3 & $\underline{1}$ & 5 \\
\hline \multicolumn{6}{|c|}{ Tersine Döndürme ile Komşuluk Üretme } \\
\hline Eski Kromozom & $\underline{1}$ & $\underline{\mathbf{2}}$ & $\underline{\mathbf{3}}$ & $\underline{4}$ & 5 \\
\hline Yeni Kromozom & $\underline{4}$ & $\underline{\overline{\mathbf{3}}}$ & $\underline{\underline{2}}$ & $\underline{1}$ & 5 \\
\hline \multicolumn{6}{|c|}{ Araya Sokma ile Komşuluk Üretme } \\
\hline Eski Kromozom & $\underline{1}$ & 2 & 3 & $\underline{4}$ & 5 \\
\hline Yeni Kromozom & $\overline{2}$ & 3 & $\underline{4}$ & $\underline{\mathbf{1}}$ & 5 \\
\hline
\end{tabular}

Çalışma kapsamında ayrıca SHAP için dışarıdan ekleme adinda yeni bir yerel arama stratejisi önerilmiştir. $\mathrm{Bu}$ stratejinin diğer üç komşuluk üreten yaklaşımdan fark1 ise kromozomda yer almayan hedefleri de göz önüne alabilmesidir. Diğer üç komşuluk üreten yaklaşımda sadece olası çözümü ifade eden kromozom yapısında yer alan hedeflerin farkl1 silahlara atanma durumu araştırılabilirken, çalışmada önerilen yaklaşımda problemde olup kromozomda olmayan hedefler de kullanılarak bu kısıtlama aşılabilmiştir. Önerilen dışarıdan ekleme yerel arama yaklaşımında kromozomda olmayan hedefler kromozomda birden fazla yer alan hedeflerin yerine rassal olarak yerleştirilerek yeni kromozomlar üretilmektedir. Her bir iterasyonda ilgili kromozomda tekrarlayan hedef sayısı ile olmayan hedef sayısının çarpımı kadar dışarıdan ekleme stratejisiyle yeni kromozomlar elde edilmiştir. Tablo 4'te dışarıdan ekleme yaklaşımına dair bir örnek verilmiştir.
Tablo 4. Dışarıdan ekleme yaklaşımı

\begin{tabular}{l|l|l|l|l|l}
\hline Eski Kromozom & 4 & 5 & $\underline{\mathbf{1}}$ & 3 & $\underline{\mathbf{1}}$ \\
\hline Yeni Kromozom & 4 & 5 & $\underline{\mathbf{2}}$ & 3 & $\underline{\mathbf{1}}$ \\
\hline
\end{tabular}

Komşuluk üreten yaklaşımlarda SHAP örneklerinde kromozom uzunluğunu belirleyen silah sayısı $\mathrm{n}$ için tüm olası komşuluklar üretilmekte ve bu durumda $n^{*}(n-1) / 2$ sayıda yeni komşu kromozom üretilmektedir. Yerel arama sonucunda daha iyi kromozom elde edilebilirse popülasyona dahil edilmektedir.

SHAP için bu çalışmada kullanılan algoritmalar; klasik GA, komşuluk üreten üç yaklaşım ile yerel aramaya dayanan YGA1, dişarıdan ekleme ve komşuluk üreten üç yaklaşımı birlikte kullanan ve tarafımızca önerilen yaklaşım olan YGA2 olmuştur. 


\section{Bulgular}

Çalışmada önerilen yaklaşımların problemde çözüm performanslarını analiz etmek için literatürdeki bazı SHAP örnekleri ve ayrica açıklayıcı bir örnek problem (P) kullanılmıştır. SHAP için çalışma kapsamında oluşturulan 5 adet silah tipi ve 5 adet hedeften oluşan sayısal örneğe dair bilgiler Tablo 5'te verilmiştir.

Tablo 5. SHAP sayısal örnek (P)

\begin{tabular}{llllll}
\hline Silah Hasar Olasılıkları & \multicolumn{3}{l}{} \\
\hline Silah Tipleri & \multicolumn{1}{l}{ Hedefler } & & 3 & 4 & 5 \\
\cline { 2 - 6 } & 1 & 2 & 0.4 & 0.3 & 0.35 \\
\cline { 2 - 6 } & 0.5 & 0.45 & 0.3 & 0.35 & 0.5 \\
3 & 0.45 & 0.4 & 0.35 & 0.5 & 0.45 \\
4 & 0.4 & 0.3 & 0.5 & 0.45 & 0.4 \\
5 & 0.3 & 0.35 & 0.45 & 0.4 & 0.3 \\
\hline Hedef Değerleri & 0.35 & 0.5 & 0.87 & 1.22 & 0.94 \\
\hline
\end{tabular}

Öte yandan, Lu vd., (2006) tarafindan yapilan çalışmada kullanılan örnek 'L1', Hongtao ve Fengju (2016) tarafından oluşturulan problem 'H1', Sonuc vd., (2017) tarafindan kullanılan 11 adet problem ise WT1,.., WT11 adlar1 ile bu çalışmada kullanılmıştır.

Problemler önerilen YGA2, YGA1 ve standart GA ile ayrı ayrı 10'ar kez çözülmüştür. Tüm algoritmalara dair çözümler MATLAB ortamında, Intel(R) Core(TM) i5-3210M CPU @ 2.50GHz, $2501 \mathrm{Mhz}, 2$ Çekirdek, 4 Mantıksal İşlemciye ve toplamda 8GB Ram'e sahip bilgisayar ortamında elde edilmiştir. Algoritmalarda kullanılan popülasyon büyüklüğü 20 kromozom olurken maksimum iterasyon sayıs1 2000 olarak belirlenmiştir. Tüm problemlerin algoritmalara göre elde edilen çözüm sonuçları Tablo 6'daki gibi gerçekleşmiştir. Tablo 6'da örneklerin bilinen en iyi çözümleri ile algoritmalarla elde edilen en iyi çözümler arasındaki fark yüzdesi sapma oranı olarak ifade edilirken, algoritma çalışma süreleri ise saniye cinsinden aktarılmıştır.

Tablo 6'daki sonuçlara göre tüm algoritmalar P1, L1, H1, WT1 ve WT2 için bilinen en iyi sonuca ulaşabilmişlerdir. YGA1 ve önerilen metot YGA2, ayrıca WT3 için de bilinen en iyi değeri bulabilirken diğer problemlerin hiçbirinde en iyi sonuca ulaşabilen algoritma olmamıştır. Fakat YGA2 algoritmas1, WT6 örneği dişında tüm problemlerde diğer algoritmalarla eşit veya daha iyi sonuca ulaşabilmiştir. Öte yandan YGA2 ile en fazla \% 3.2 sapma oranı elde edilmiş ve bilinen sonuçlara oldukça yakın değerler bulunmuştur. YGA1'de ise maksimum sapma oran $1 \% 9.5$ ve GA'da ise \% 21.8 olarak gerçekleşmiş ve bu durumda sonuçların kabul edilebilir olarak düşünülmesi oldukça zordur. Algoritmaların çalışma süreleri bakımından GA oldukça kısa sürede sonuca ulaşabilmekte fakat elde edilen sonuçlar kabul edilmekten uzakta kalmaktadır. YGA1 ve YGA2 süreler bakımından problemlere göre değişken çalışma zamanlarına sahip olurken genel olarak benzer sürelerde tamamlanmaktadırlar.

Literatürdeki çalışmalarla algoritma sonuçları birlikte değerlendirildiğinde; Lu vd., (2006) tarafından L1 için ifade edilen optimum değer minimum yönlü model için 0.537 'ye tekabül etmekteyken, önerdikleri yöntem olan iyileştirilmiş GA ile tüm denemelerinde bu değere ulaşamadıklarını ifade etmişlerdir. L1 için çalışmada tüm algoritmalarla her bir denemede en iyi sonuca ulaşılabilmiş ve bu açıdan algoritmaların Lu vd., (2006)'ya göre üstünlügü ortaya konmuştur. Hongtao ve Fengju (2016) tarafindan kullanılan $\mathrm{H} 1$ için ise minimum yönlü modelde elde edilebilecek optimum değerlere her üç algoritma ile tüm denemelerde ulaşılabilmiştir. $\mathrm{Bu}$ durumda çalışmada önerilen yöntemin literatürdeki diğer algoritmalarla yarışabilir düzeyde olduğu ortaya çıkmıştır. Son olarak Sonuç vd., (2017), Kutucu ve Durgut (2018) ve Sonuç (2020) tarafindan kullanılan problemlerden WT1, WT2 ve WT3 için önerilen yaklaşım YGA2 ile bilinen en iyi sonuca ulaşılabilmiştir. Problemdeki boyut sayısı büyüdükçe ise optimum değerlere ulaşabilmek mümkün olmamıştır. Sonuç vd., (2017), Kutucu ve Durgut (2018) ve Sonuç (2020) tüm problemlerde çok iyi sonuçlar elde etmişlerdir. Fakat kullandıkları algoritmaların çözüm yapıları ve sundukları matematiksel modeller incelendiğinde, problemleri her hedefe en az bir tane silah atanacak ve her silah ise en fazla bir 
hedefe yönelecek şekilde kısıtlayarak basit doğrusal atama modeli olarak çözmüşlerdir. $\mathrm{Bu}$ şekilde gerçekte olan çözüm uzayından çok daha küçük bir alanı tarayarak her bir denemede optimum sonuca ulaşabilmişlerdir. Çalışma dahilinde ise bu örnekler sadece SHAP'ta yer alan kısıtlamalar kullanılarak çözülmüş ve bu durumda çözüm uzayı çok daha büyük olmuştur. Bu nedenle önerdikleri algoritmalarla, çalışmadaki SHAP için önerilen algoritmaları karşılaştırmak anlamsız olacağ 1 için bir kıyaslama mümkün olmamıştır. Bu durumu P1 örneği ile açıklamak gerekirse çalışmada elde edilen çözüm yapısı 1-1-1-4-2 şeklinde, sadece üç hedef içermekte ve iki hedef çözümde bulunmamaktadır. $\mathrm{Bu}$ haliyle 4.001 değerine ulaşılabilmiştir. Sonuç vd., (2017), Kutucu ve Durgut (2018) ve Sonuç (2020) tarafından önerilen yaklaşımlarla ise 1-5-4-3-2 yapısına ulaşılabilmekte ve bu durumda daha kötü bir değer olan 5.085 elde edilmektedir.

Tablo 6. Test problemlerinin yöntemlere göre sonuçları

\begin{tabular}{|c|c|c|c|c|c|c|c|c|c|}
\hline Örnek & Silah & Hedef & $\begin{array}{l}\text { Bilinen En } \\
\text { iyi Değer }\end{array}$ & Algoritma & $\begin{array}{l}\text { En İyi } \\
\text { Değer }\end{array}$ & $\begin{array}{l}\text { Sapma } \\
\text { Oranı } \\
(\%)\end{array}$ & $\begin{array}{l}\text { Ortalama } \\
\text { Değer }\end{array}$ & $\begin{array}{l}\text { En Kötü } \\
\text { Değer }\end{array}$ & Süre \\
\hline \multirow[t]{3}{*}{$\mathrm{P} 1$} & 5 & 5 & 4.001 & GA & 4.001 & 0 & 4.001 & 4.001 & 12 \\
\hline & & & & YGA1 & 4.001 & 0 & 4.001 & 4.001 & 21 \\
\hline & & & & YGA2 & 4.001 & 0 & 4.001 & 4.001 & 30 \\
\hline \multirow[t]{3}{*}{ L1 } & 11 & 7 & 0.537 & GA & 0.537 & 0 & 0.537 & 0.537 & 14 \\
\hline & & & & YGA1 & 0.537 & 0 & 0.537 & 0.537 & 73 \\
\hline & & & & YGA2 & 0.537 & 0 & 0.537 & 0.537 & 76 \\
\hline \multirow[t]{3}{*}{$\mathrm{H} 1$} & 7 & 10 & 0.325 & GA & 0.325 & 0 & 0.325 & 0.325 & 8 \\
\hline & & & & YGA1 & 0.325 & 0 & 0.325 & 0.325 & 34 \\
\hline & & & & YGA2 & 0.325 & 0 & 0.325 & 0.325 & 32 \\
\hline \multirow[t]{3}{*}{ WT1 } & 5 & 5 & 48.364 & GA & 48.364 & 0 & 48.364 & 48.364 & 9 \\
\hline & & & & YGA1 & 48.364 & 0 & 48.364 & 48.364 & 17 \\
\hline & & & & YGA2 & 48.364 & 0 & 48.364 & 48.364 & 27 \\
\hline \multirow[t]{3}{*}{ WT2 } & 10 & 10 & 96.312 & GA & 96.312 & 0 & 99.707 & 105.601 & 11 \\
\hline & & & & YGA1 & 96.312 & 0 & 96.312 & 96.312 & 63 \\
\hline & & & & YGA2 & 96.312 & 0 & 96.312 & 96.312 & 58 \\
\hline \multirow[t]{3}{*}{ WT3 } & 20 & 20 & 142.107 & GA & 146.888 & 0.033 & 151.374 & 159.023 & 11 \\
\hline & & & & YGA1 & 142.107 & 0 & 143.208 & 148.35 & 206 \\
\hline & & & & YGA2 & 142.107 & 0 & 142.449 & 142.815 & 170 \\
\hline \multirow[t]{3}{*}{ WT4 } & 30 & 30 & 248.029 & GA & 257.893 & 0.038 & 264.7574 & 274.0722 & 11 \\
\hline & & & & YGA1 & 248.422 & 0.002 & 250.8647 & 259.2695 & 496 \\
\hline & & & & YGA2 & 248.331 & 0.001 & 250.2192 & 251.9293 & 438 \\
\hline \multirow[t]{3}{*}{ WT5 } & 40 & 40 & 305.502 & GA & 327.226 & 0.066 & 336.4 & 344.953 & 15 \\
\hline & & & & YGA1 & 307.018 & 0.005 & 311.547 & 325.318 & 1012 \\
\hline & & & & YGA2 & 306.7 & 0.004 & 309.464 & 316.65 & 815 \\
\hline \multirow[t]{3}{*}{ WT6 } & 50 & 50 & 353.01 & GA & 384.309 & 0.081 & 405.695 & 417.366 & 19 \\
\hline & & & & YGA1 & 357.294 & 0.012 & 369.199 & 387.951 & 1809 \\
\hline & & & & YGA2 & 358.5 & 0.015 & 360.739 & 364.66 & 1408 \\
\hline \multirow[t]{3}{*}{ WT7 } & 60 & 60 & 414.222 & GA & 472.281 & 0.123 & 492.004 & 532.345 & 21 \\
\hline & & & & YGA1 & 422.1 & 0.019 & 441.644 & 452.61 & 2347 \\
\hline & & & & YGA2 & 419.05 & 0.012 & 422.577 & 425.63 & 2317 \\
\hline \multirow[t]{3}{*}{ WT8 } & 70 & 70 & 496.31 & GA & 565.529 & 0.122 & 600.446 & 637.407 & 19 \\
\hline & & & & YGA1 & 509.8 & 0.027 & 535.389 & 556.47 & 4474 \\
\hline & & & & YGA2 & 506.07 & 0.019 & 510.602 & 516.07 & 3627 \\
\hline \multirow[t]{3}{*}{ WT9 } & 80 & 80 & 531.159 & GA & 644.305 & 0.176 & 658.716 & 678.804 & 21 \\
\hline & & & & YGA1 & 556.3 & 0.045 & 572.279 & 598.25 & 6116 \\
\hline & & & & YGA2 & 545.54 & 0.026 & 550.889 & 555.1 & 5137 \\
\hline WT10 & 90 & 90 & 589.321 & GA & 726.559 & 0.189 & 760.41 & 790.408 & 26 \\
\hline
\end{tabular}




\begin{tabular}{cccccccccc} 
& & & & YGA1 & 623.2 & 0.054 & 659.564 & 682.83 & 8770 \\
& & & YGA2 & $\mathbf{6 0 6 . 1 6}$ & 0.028 & 609.63 & 615.28 & 6863 \\
\hline \multirow{2}{*}{ WT11 } & \multirow{2}{*}{100} & \multirow{2}{*}{100} & \multirow{2}{*}{694.501} & GA & 887.683 & 0.218 & 910.262 & 953.096 & 28 \\
& & & & YGA1 & 767.61 & 0.095 & 769.348 & 774.56 & 11843 \\
& & & & YGA2 & $\mathbf{7 1 7 . 6 9}$ & 0.032 & 718.938 & 722.68 & 10398 \\
\hline
\end{tabular}

\section{Tartışma ve sonuçlar}

SHAP, çok farklı alanlarda kullanılan bir temel matematiksel model olmakla birlikte en çok askeri alanda uygulamalarına rastlanan doğrusal olmayan fonksiyonlara sahip bir problemdir. Problem kesin çözüm veren yöntemlerle çözülmeye çalışıldığında oldukça etkisiz sonuçlar elde edilmekte ve modelin boyutu büyüdükçe bu durum daha da net hale gelmektedir. $\mathrm{Bu}$ nedenle yapılan çalışmalarda, yaklaşık iyi çözümler üreten sezgisel yöntemlere genellikle başvurulmaktadır. GA ise sezgisel yöntemler içerisinde problemlere kolay adapte olabilen ve yüksek performansa sahip yapısıyla bilinmektedir. Öte yandan yerel arama ile desteklenen melez GA'larda başarım anlamlı biçimde artmaktadır. Problemlere özgü iyileştirmeler ise melez GA gibi yöntemlerin başarısını daha da artırmaktadır.

Çalışma kapsamında geliştirilen YGA2, klasik komşuluk üretmeye dayalı yerel arama yaklaşımı içeren YGA1'e nazaran çözüm yapısında bulunmayan hedefleri çözüme ekleyebilme seçeneği ile SHAP için daha uygun yerel arama stratejisine sahiptir. Örnek problemlerin çözümünde YGA2 yaklaşımı standart GA'dan ve YGA1'den daha iyi sonuçlar üretirken ek olarak literatürdeki algoritmalarla da rekabet edebilir olduğunu göstermiştir. Gelecekteki yapılacak çalışmaların probleme özel, algoritma aşamalarında geliştirilecek özgün yaklaşımlarla problemin çözüm performansında daha yüksek başarımı sağlayabileceği düşünülmektedir.

\section{Kaynaklar}

Ahuja, R. K., Kumar, A., Jha, K. C. and Orlin, J. B. (2007). Exact and heuristic algorithms for the weapon-target assignment problem. Operations Research, 55(6), 1136-1146. https://doi.org/10.1287/opre.1070.0440.

Cetin, E. and Esen, S. T. (2006). A weapon-target assignment approach to media allocation. Applied Mathematics and Computation, 175(2), 1266-1275.

https://doi.org/10.1016/j.amc.2005.08.041.

Chang, T., Kong, D., Hao, N., Xu, K. and Yang, G. (2018). Solving the dynamic weapon target assignment problem by an improved artificial bee colony algorithm with heuristic factor initialization. Applied Soft Computing, 70, 845863. https://doi.org/10.1016/j.asoc.2018.06.014.

Fu, T. P., Liu, Y. S., and Chen, J. H. (2006). Improved genetic and ant colony optimization algorithm for regional air defense wta problem. First International Conference on Innovative Computing, Information and Control (ICICIC'06) (ss. 226-229). IEEE. https://doi.org/10.1109/ICICIC.2006.99.

Hocaoğlu, M. F. (2019). Weapon target assignment optimization for land based multi-air defense systems: A goal programming approach. Computers \& Industrial Engineering, 128, 681689. https://doi.org/10.1016/j.cie.2019.01.015.

Hoff, A., Løkketangen, A. and Mittet, I. (1996). Genetic algorithms for $0 / 1$ multidimensional knapsack problems, Proceedings Norsk Informatikk Konferanse (NIK'96) (ss. 291-301). Brietvien.

Holland J, H. (1975). Adaptation İn Natural And Artificial Systems. (Vol 1). Ann Arbor: University of Michigan Press.

Hongtao, L. and Fengju, K. (2016). Adaptive chaos parallel clonal selection algorithm for objective optimization in WTA application. OptikInternational Journal for Light and Electron Optics, 127(6), 3459-3465. https://doi.org/10.1016/j.ijleo.2015.12.122.

Hu, X., Luo, P., Zhang, X. and Wang, J. (2018). Improved ant colony optimization for weapontarget assignment. Mathematical Problems in Engineering, 2018, 1-14. https://doi.org/10.1155/2018/6481635.

Kline, A., Ahner, D. and Hill, R. (2019). The weapontarget assignment problem. Computers \& Operations Research. 105, 226-236. https://doi.org/10.1016/j.cor.2018.10.015

Kutucu, H. ve Durgut, R. (2018). Silah hedef atama problemi için tavlama benzetimli bir hibrit yapay ar1 kolonisi algoritmasi. Süleyman Demirel Üniversitesi Fen Bilimleri Enstitüsü Dergisi, 22, Özel Say1, 263-269. https://doi.org/10.19113/sdufbed.39561.

Lee, Z. J., Lee, C. and Su, S. F. (2002). An immunitybased ant colony optimization algorithm for solving weapon-target assignment problem. Applied Soft Computing, 2(1), 39-47. https://doi.org/10.1016/S1568-4946(02)00027-3 
Lee, Z. J., Su, S. F. And Lee, C. Y. (2003). Efficiently solving general weapon-target assignment problem by genetic algorithms with greedy eugenics. IEEE Transactions on Systems, Man, and Cybernetics, Part B (Cybernetics), 33(1), 113-121.

https://doi.org/10.1109/TSMCB.2003.808174.

Li, Y., Kou, Y., Li, Z., Xu, A. and Chang, Y. (2017). A modified pareto ant colony optimization approach to solve biobjective weapon-target assignment problem. International Journal of Aerospace Engineering, $2017 . \quad 1-14$. https://doi.org/10.1155/2017/1746124

Li, X., Zhou, D., Pan, Q., Tang, Y. and Huang, J. (2018). Weapon-target assignment problem by multiobjective evolutionary algorithm based on decomposition. Complexity, 2018. 1-19. https://doi.org/10.1155/2018/8623051.

Lu, H., Zhang, H., Zhang, X. and Han, R. (2006). An improved genetic algorithm for target assignment, optimization of naval fleet air defense. 6th World Congress on Intelligent Control and Automation (ss. 3401-3405). IEEE. Dalian.

Manne, A. S., 1958. A target-assignment problem. Operations Research, 6(3), 346-351. https://doi.org/10.1287/opre.6.3.346.

Sonuc, E., Sen, B. and Bayır, S. (2017). A parallel simulated annealing algorithm for weapon-target assignment problem. International Journal of Advanced Computer Science and Applications, 8(4), 87-92.

Sonuç, E. (2020). A modified crow search algorithm for the weapon-target assignment problem. An
International Journal of Optimization and Control: Theories \& Applications (IJOCTA), 10(2), 188-197. https://doi.org/10.11121/ijocta.01.2020.00775.

Wang, C., Fu, G., Zhang, D., Wang, H. and Zhao, J. (2019). Genetic algorithm-based variable value control method for solving the ground target attacking weapon-target allocation problem. Mathematical Problems in Engineering, 2019, 19. https://doi.org/10.1155/2019/6761073

Yang, S., Yang, M., Wang, S. and Huang, K. (2016). Adaptive immune genetic algorithm for weapon system portfolio optimization in military big data environment. Cluster Computing, 19(3), 13591372. https://doi.org/10.1007/s10586-016-05963.

Yanxia, W., Longjun, Q., Zhi, G. and Lifeng, M. (2008). Weapon target assignment problem satisfying expected damage probabilities based on ant colony algorithm. Journal of Systems Engineering and Electronics, 19(5), 939-944. https://doi.org/10.1016/S1004-4132(08)601796.

Zeng, X., Zhu, Y., Nan, L., Hu, K., Niu, B. and He, X. (2006). Solving weapon-target assignment problem using discrete particle swarm optimization. 6th World Congress on Intelligent Control and Automation (ss. 3562-3565). IEEE. Dalian.

Zhou, Y., Li, X., Zhu, Y. and Wang, W. (2016). A discrete particle swarm optimization algorithm applied in constrained static weapon-target assignment problem. 12th World Congress on Intelligent Control and Automation (WCICA) (ss.3118-3123). IEEE. Guilin. 